\title{
THỜI GIAN SỐNG THÊM KHÔNG BỆNH VÀ CÁC YẾU TỐ LIÊN QUAN CỦA HÓA TRI BÔ TRƠ DOCETAXEL - CYCLOPHOSPHAMID TRÊN UNG THƯ VÚ CAO TUỔI
}

\section{TÓM TẮT}

Mục tiêu: Đánh giá thời gian sống thêm không bệnh (DFS) và các yếu tố liên quan của hóa trị bổ trợ phác đồ Docetaxel kết hợp Cyclophosphamid trên bệnh nhân ung thư vú cao tuổi điều trị tại bệnh viện K. Đối tượng nghiên cứu: 70 bệnh nhân nữ cao tuổi được chẩn đoán là ung thư vú giai đoạn I-IIIA, được phẩu thuât cắt toàn bố tuyến vú hoăc phẫu thuất bảo tôn kèm vét hạch nách hệ thống điều trị bổ trợ hóa chất phác đồ Docetaxel kết hợp Cyclophosphamid (TC) tại bệnh viện $K$ từ tháng 01/2013- 12/2018. Phương pháp nghiên cứu: Mồ tả hồi cứu. Kết quả: Tuổi trung bình của các bệnh nhân trong nghiên cứu là $64,74 \pm 3,94$ tuổi, trong đó $67,1 \%$ bệnh nhân có tiền sử bệnh lý tim mạch. Tỷ lệ sống thêm không bênh tai thời điểm 3 năm, 5 năm lần lướt là $87,7 \%$ và $81 \%$. Giai đoạn bệnh và phân nhóm sinh học phân tử có liên quan đến DFS $(p<0,05)$. DFS không có sự khác biệt giữa 2 nhóm có và không có bệnh lý tim mạch ( $p>0,05)$. Kết luâan: Điều trị bổ trợ phác đô Docetaxel kết hợp Cyclophosphamid (TC) trên bệnh nhân UTV cao tuổi có tỷ lệ sống thêm không bệnh cao và nên được cân nhắc trong thực hành lâm sàng, đặc biệt trong nhóm bệnh nhẩn có bệnh lý tim mach.

Tư khóa: Ung thư vú, cao tuổi, hóa trị bổ trợ, Docetaxel, Cyclophosphamid.

\section{SUMMARY}

DISEASE FREE SURVIVAL AND

ASSOCIATED FACTORS OF ADJUVANT CHEMOTHERAPY DOCETAXEL AND CYCLOPHOSPHAMID (TC) REGIMEN IN

ELDERLY BREAST CANCER PATIENTS

Aims: Our study aimed to evaluate disease free survival and associated factorsof adjuvant chemotherapy Docetaxel and Cyclophosphamid (TC) regimen in elderly breast cancer patients treated at $\mathrm{K}$ hospital. Population: 70 patients were women, ages $\geq 60$, diagnosed breast cancer, treated by surgery mastectomy and adjuvant DocetaxelCyclophosphamid regimen at K hospital from 01/201312/2018. Methods: Retrospective description. Results: The mean age was $64.74 \pm 3.94$ (range 60 to $74,67,1 \%$ had cardiovascular disease. 3-year and 5 -year disease free survival were $87.7 \%$ and $81.1 \%$ respectively. DFS was associated with stage and molecular subtype $(p<0.05)$. DFS was not significantly

*Bệnh viện $K$ Tân Triều

Chịu trách nhiệm chính: Phùng Thị Huyền

Email: phungthihuyen@gmail.com

Ngày nhận bài: 6.5.2021

Ngày phản biên khoa học: 25.6.2021

Ngày duyệt bài: 9.7.2021 different between those with and without cardiovascular disease $(p>0.05)$. Conclusion: Treatment adjuvant chemotherapy TC regimen in elderly patients has a high DFS rate and should be considered in clinical practice, especially for patients with cardiovascular disease.

Key words: Breast cancer, elderly, adjuvant chemotherapy, Docetaxel, Cyclophosphamid.

\section{I. ĐĂT VẤN ĐỀ}

Ung thư vú (UTV) là căn bệnh ung thư phổ biến nhất và nguyên nhân gây tử vong hàng đâu do ung thư ở phụ nữ ở nhiều nước trên thế giới [1]. Theo ghi nhận tại Việt Nam năm 2010 có 12.533 trường hợp mới mắc UTV với tỷ lệ mắc chuẩn theo tuổi là 29,9/100.000 dân và 5339 người tử vong do căn bệnh này [2]. Mặc dù có nhiêu tiến bộ trong điêu trị, mức độ giảm tỷ lệ tử vong ở nhóm bênh nhân (BN) cao tuổi khá hạ chế $(1,5 \% /$ năm) so với nhóm bệnh nhân trẻ 20 39 tuổi $(2,8 \% /$ năm) [3].

Tuổi thọ trung bình của dân số nước ta tăng dân qua các giai đoạn và ước tính tỷ lệ người cao tuổi sẽ tăng gấp 3 vào năm 2050 [4]. Tỷ lệ người cao tuổi tăng dẫn đến tỷ lệ bệnh nhân ung thư vú ở người cao tuổi cũng tăng dân. Tuy nhiên các nghiên cứu về điều trị bổ trợ ung thư vú hiện nay vẫn tập trung chủ yếu ở nhóm bệnh nhân trẻ, còn ít các nghiên cứu thực hiện trên nhóm bệnh nhân cao tuổi. Trong khi đó, nhóm cao tuổi có tỷ lệ mắc ung thư vú tăng dân theo tuổi đồng thời tỷ lệ có các bệnh đồng thời cao hơn so với các bệnh nhân trẻ, đặc biệt là bệnh lý tim mach. Vì vâyy lựa chọn hóa chất cho các bệnh nhân cao tuổi cân phải được cân nhắc kĩ, đặc biệt là Anthracyclin do gây độc tính tích lũy trến tim mach [5]. Tai Viêt Nam, chưa có nghiên cứu nào về hiệu quả điều trị bổ trợ của phác đồ Docetaxel- Cyclophosphamid trên bệnh nhân ung thư vú cao tuổi. Chính vì vậy, chúng tôi tiến hành nghiên cứu này với mục tiêu đánh giá thời gian sống thêm không bệnh và các yếu tố liên quan của phác đồ hóa trị bổ trợ DocetaxelCyclophosphamid cho ung thư vú ở bệnh nhân nữ cao tuổi tại bệnh viện K.

\section{II. ĐỐI TƯợNG VÀ PHƯƠNG PHÁP NGHIÊN CỨU}

2.1. Đối tượng nghiên cứu. Nghiên cứu được thực hiện trên 70 bệnh nhân ung thư vú được điều trị bổ trợ hóa chất phác đồ Docetaxel 
kết hợp Cyclophosphamid (TC) tại bệnh viện K từ tháng 01/2013 đến 12/2018.

Tiêu chuẩn lựa chọn bệnh nhân:

- BN nữ từ 60 tuổi trở lên.

- Chẩn đoán mô bệnh học: UTBM tuyến vú.

- Chẩn đoán ung thư vú giai đoạn I-III theo phân loại của hiệp hội ung thư Hoa Kỳ AJCC 8.

- Đã được phẫu thuật cắt toàn bộ tuyến vú hoặc phẫu thuật bảo tôn kèm vét hạch nách hệ thống và điều trị xạ trị, nội tiết khi có chỉ định.

- Điều trị tối thiểu 3 chu kỳ hóa chất với phác đồ Docetaxel- Cyclophosphamid

- Chỉ số toàn trạng $\leq 2$ theo thang điểm ECOG.

- Chức năng tuỷ xương, gan, thận trong giới hạn bình thường. điều trị.

- Có đây đủ hồ sơ bệnh án ghi nhận quá trình

\section{Tiêu chuẩn loại trừ bệnh nhân:}

- Bệnh nhân bỏ điều trị.

- BN có Her-2 dương tính được điêuu trị Trastuzumab.

- BN mắc bệnh ung thư khác kèm theo

- Các bệnh cấp và mạn tính trâm trọng, có nguy cơ tử vong gân

\subsection{Phương pháp nghiên cứu} cứu

Thiết kế nghiên cứu: Nghiên cứu mô tả hôi

Các chỉ số nghiên cứu: Thu thập số liệu, thông tin bệnh nhân theo mẫu bệnh án nghiên cứu dựa trển các ghi nhận trên hồ sơ bệnh án bao gổm tuổi, toàn trạng, bệnh lý kèm theo, giai đoạn, phân nhóm sinh học, các phương pháp điêu trị, thời gian sống thêm không bệnh, toàn bộ và các yếu tố liên quan.

\section{Phác đồ điều tri:}

- Docetaxel 75 mg/m2 diện tích da, pha với $250 \mathrm{ml}$ dung dịch glucose $5 \%$ hoặc natriclorua 0,9\% truyên tĩnh mạch trong vòng 3h, ngày 1 .

- Cyclophosphamid 600 mg/m2 diện tích da, pha với $200 \mathrm{ml}$ dung dịch glucose $5 \%$ hoặc natriclorua $0,9 \%$ truyền tĩnh mạch trong vòng 30 phút, ngày 1 .

- Điêu trị hóa chất phác đồ 4 chu kỳ cho nhóm bệnh nhân yếu tố nguy cơ thấp: giai đoạn I-IIA, chưa di căn hạch, độ mô học thấp, phân nhóm sinh học phân tử Luminal $A$, Luminal $B$.

- Điều trị hóa chất bổ trợ phác đồ 6 chu kỳ cho bệnh nhân có yếu tố nguy cơ cao: giai đoạn IIB-III, u kích thước lớn > 3cm, di căn hạch, độ mô học cao, nhóm Her2/neu dương tính hoặc Basal-like.

2.3. Xử lý số liệu. Các số liệu thu thập được mã hóa và xử lý bằng phân mềm SPSS 20.0

- Phân tích thời gian sống thêm dựa theo ước tính Kaplan-Meier.

- Kiểm định so sánh sự khác biệt về khả năng sống thêm với một số yếu tố liên quan bằng kiểm định Log-rank.

\section{KẾT QUẢ NGHIÊN CỨU}

Bảng 1. Đặc điểm bệnh nhân nghiên cưu

\begin{tabular}{|c|c|c|c|}
\hline \multicolumn{2}{|c|}{ Đăc điếm } & Số BN & Tỷ lệ \\
\hline \multicolumn{2}{|c|}{ Tuối (trung bình \pm SD) } & \multicolumn{2}{|c|}{$64,74 \pm 3,94$} \\
\hline \multirow{3}{*}{$\begin{array}{l}\text { Toàn trạng } \\
\text { PS }\end{array}$} & 0 & 45 & 64,3 \\
\hline & 1 & 23 & 32,8 \\
\hline & 2 & 2 & 2,9 \\
\hline \multirow{2}{*}{$\begin{array}{l}\text { Bệnh mạn tính } \\
\text { kèm theo }\end{array}$} & Không & 19 & 27,1 \\
\hline & Có & 51 & 72,9 \\
\hline \multirow{2}{*}{$\begin{array}{l}\text { Bệnh lý tim } \\
\text { mạch }\end{array}$} & Không & 23 & 32,9 \\
\hline & Có & 47 & 67,1 \\
\hline \multirow{3}{*}{ Giai đoạn } & I & 15 & 21,4 \\
\hline & II & 52 & 74,3 \\
\hline & III & 3 & 4,3 \\
\hline \multirow{4}{*}{$\begin{array}{l}\text { Nhóm sinh học } \\
\text { phân tử }\end{array}$} & Luminal $\mathrm{A}$ & 15 & 21,4 \\
\hline & Luminal B & 23 & 32,9 \\
\hline & Her2 (+) & 24 & 34,3 \\
\hline & Basal like & 8 & 11,4 \\
\hline
\end{tabular}

Tuổi trung bình trong nghiên cứu này là 64,74 , chủ yếu các bệnh nhân có PS 0-1. Có 51 BN trong nghiên cứu có kèm theo ít nhất 1 bệnh mạn tính khác, chiếm 72,9\%. Giai đoạn bệnh II gặp nhiều nhất (74,3\%), số BN ở giai đoạn I là 21,4\%. Phân nhóm sinh học phân tử Her2 dương tính chiếm tỷ lệ cao nhất 34,3\%, nhóm Luminal $A$ chỉ chiếm 21,4\%, nhóm Luminal $B$ và nhóm Basal- like chiếm lần lượt 32,9\% và $11,4 \%$.

Bảng 2: Các phương pháp điều trị

\begin{tabular}{|c|c|c|}
\hline Phương pháp điêuu trị & $\begin{array}{c}\text { Số bềnh } \\
\text { nhẩn }\end{array}$ & $\begin{array}{c}\text { Tỉ lệ } \\
\mathbf{\%}\end{array}$ \\
\hline $\begin{array}{c}\text { Phâu thuật cắt tuyến } \\
\text { vú triệt căn }\end{array}$ & 66 & 94,3 \\
\hline Phấu thuật bảo tồn & 4 & 5,7 \\
\hline Xạ trị & 34 & 48,6 \\
\hline Điều trị nội tiết & 38 & 54,3 \\
\hline Điều trị đích & 0 & 0 \\
\hline Điều trị hóa chất bố trợ & 70 & 100 \\
\hline
\end{tabular}

Tỷ lệ phấu thuật cắt tuyến vú triệt căn là 94,3\%, chỉ có 4 BN (5,7\%) được phẫu thuật bảo tồn tuyến vú. Tia xạ bổ trợ được thực hiện cho 34 bệnh nhân. Tất cả các bệnh nhân đều được điêuu trị hóa chất bổ trợ sau phẫu thuật, không có bệnh nào nào điêuu trị thuốc đích. 38 BN được điêu trị nội tiết sau khi kết thúc hóa trị và xạ trị. Một BN có thể được điều trị nhiêuu phương pháp kết hợp.

Bảng 3: Số chu ki hóa trị bổ trớ phác đđồ TC

\begin{tabular}{|c|c|c|}
\hline Số chu kỳ điêuu trị & Số BN & Tỉ lệ \% \\
\hline 4 & 33 & 47,1 \\
\hline
\end{tabular}




\begin{tabular}{|c|c|c|}
\hline 6 & 37 & 52,9 \\
\hline Tổng & $\mathbf{7 0}$ & $\mathbf{1 0 0}$ \\
\hline
\end{tabular}

Có 37 BN được điều trị 6 chu kì phác đồ TC chiếm $52,9 \%$. Tất cả BN đều hoàn thành số chu kì hóa chất cần điều trị, không có bệnh nhân phải dừng dừng hoặc bỏ điều trị.
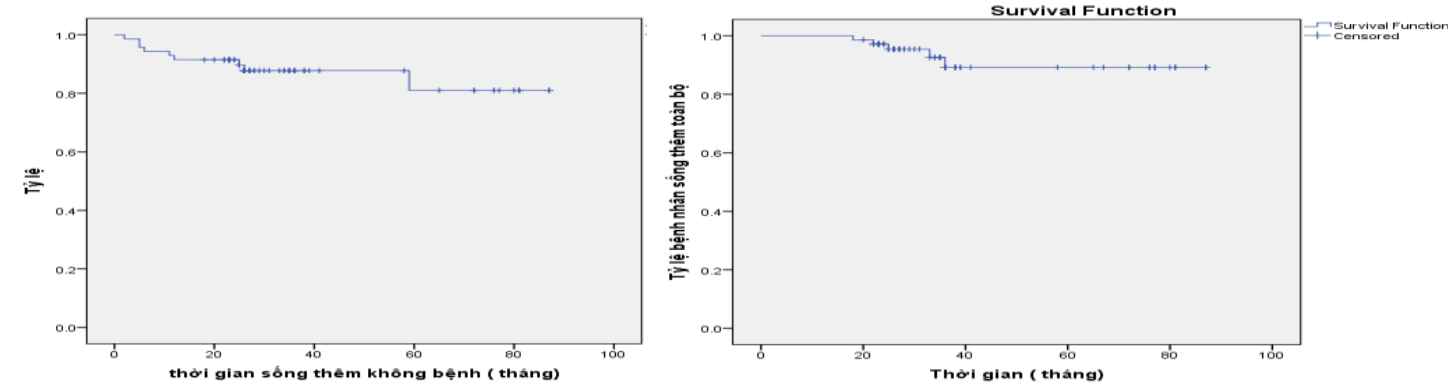

Biểu đồ 1: Biểu đồ Kaplan-Meier thời gian sống thêm không bệnh (DFS) và sông thêm toàn bô (OS)

Thời gian theo dõi trung bình 38,93 tháng có 61 BN sống thêm không tái phát tính đến thời điểm kết thúc theo dõi 87 tháng. Xác suất sống thêm không bệnh tại thời điểm 1 năm, 2 năm, 3 năm, 4 năm, 5 năm lần lượt là 94,3\%; 91,4\%; $87,7 \% ; 87,7 \% ; 81 \%$. Đến khi kết thúc nghiên cứu có 65 bệnh nhân còn sống. Tỷ lệ sống thêm toàn bộ đến thời điểm kết thúc nghiên cứu là 89,2\%.

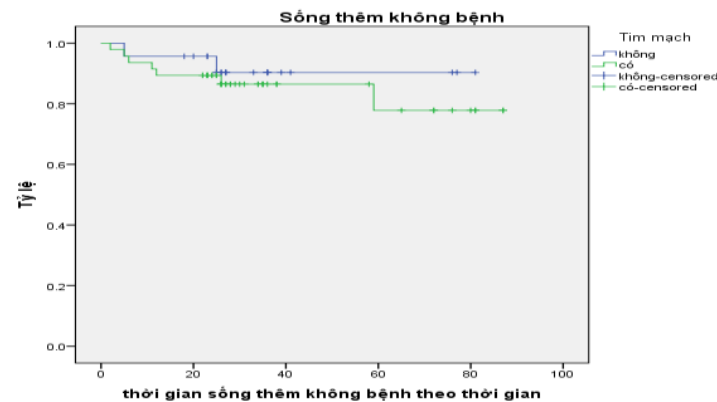

\section{Biểu đồ 2: Thời gian sống thêm không bệnh theo bệnh tim mach}

Tỷ lê sống thêm không tái phát 5 năm của nhóm bệnh nhân không mắc bệnh tim mạch là 90,3\% tháng cao hơn so với nhóm có bệnh nhân có bệnh lý tim mạch là $77,8 \%$. Tuy nhiên sự khác biệt này không có ý nghĩa thống so với nhóm có bệnh tim mạch.

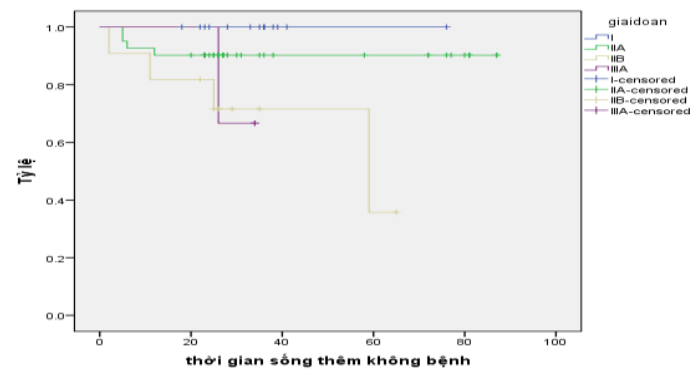

Biểu đồ 3: Thời gian sống thêm không bệnh theo giai đoạn bệnh
Thời gian sống thêm không bênh theo giai đoạn có sự khác biệt có ý nghĩa thống kê với $p=$ 0,035 . Thời gian sổng thêm không bệnh của giai đoạn I, IIA tốt hơn nhóm giai đoạn IIB, IIIA.

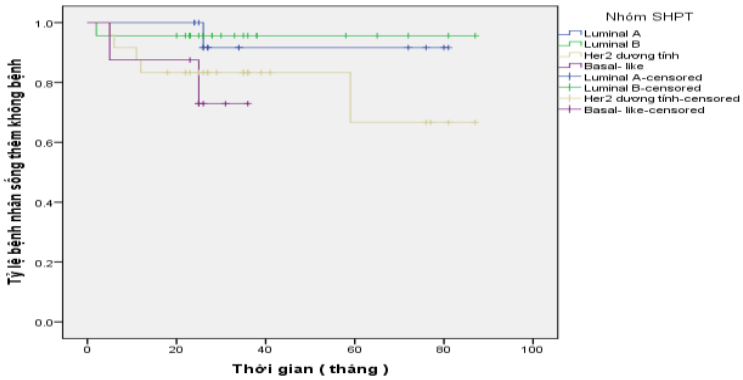

Biểu đồ 4: Thời gian sống thêm không bệnh theo nhóm sinh học phân tứ

Có 1 bệnh nhân $(6,7 \%)$ trong nhóm Luminal $A$ và 1 bệnh nhân $(4,3 \%)$ trong nhóm Luminal $B$ tái phát bệnh, tỷ lệ thấp hơn so với nhóm Her2/neu dương tính có 5 bệnh nhân tái phát $(21,8 \%)$ và nhóm Basal -like có 2 bệnh nhân tái phát (25\%). Tuy nhiên sự khác biệt giữa các nhóm chưa có khác biệt có ý nghĩa thống kê, $\mathrm{p}=0,119$.

\section{BÀN LUẬN}

Qua thống kê 70 bệnh nhân ung thư vú cao tuổi đủ tiêu chuẩn trong nghiên cứu của chúng tôi, tuổi trung bình của các bệnh nhân được điều trị bằng phác đồ TC là $64,74 \pm 3,94$, đa phần các bệnh nhân có toàn trạng tốt ( $P S=0$ chiếm $64,3 \%$, chỉ có $2 \mathrm{BN}$ có chỉ số toàn toàn trạng PS $=2$ chiếm 2,9\%). Theo Fisher với bệnh nhân dưới 40 tuổi, hóa trị bổ trợ làm giảm $37 \%$ tỷ lệ tái phát; tuổi từ 40-49 có lợi ích giảm 34\% và đến độ tuổi 70 thì hóa trị bổ trợ còn rất ít ý nghĩa trong giảm tỷ lệ tái phát cũng như lợi ích về sống thêm. Bởi vậy, việc điều trị hóa trị bổ trợ bị hạn chế đối với những BN UTV trên 70 tuổi. 
Tuy nhiên một phân tích từ nghiên cứu CALGB 49907 trên 633 BN UTV từ 65 tuổi trở lên được hóa trị bổ trợ đã chứng minh có lợi ích trong việc làm giảm tỷ lê tái phát cho BN lớn tuổi khi được hóa trị bổ trợ, đặc biệt là những $\mathrm{BN}$ thể trạng còn tốt [6].

Trong nghiên cứu của chúng tôi, có tới 72,9\% $\mathrm{BN}$ trong nghiên cứu mắc ít nhất 1 bênh lý mạn tính kèm theo trước khi điều trị UTV, trong đó bệnh lý tim mạch bao gồm tăng huyết áp, rối loạn nhịp tim, bệnh mạch vành chiếm $67,1 \%$. Nghiên cứu về mồ hình bệnh tât người cao tuổi năm 2015 tại Việt Nam cho thấy tỷ lệ mắc bệnh mạn tính và bệnh tim mach của người cao tuổi tại Việt Nam là $42 \%$ và $15 \%$ [7]. Lựa chọn quyết định điều trị và phác đồ hóa chất bổ trợ ở bệnh nhân cao tuổi, đặc biệt là các BN có bệnh lý tim mạch cần cân nhắc các thuốc ít hoặc không gây độc tính lên tim, nhằm mang lại lợi ích về giảm tái phát và kéo dài thời gian sống thêm mà không làm nặng thêm các bệnh kèm theo.

Với thời gian theo dõi trung bình là 38,9 tháng, chúng tôi cho kêt quả sống thêm không bệnh tại thời điểm 1 năm, 2 năm, 3 năm, 4 năm, 5 nămlần lượt là $94,3 \% ; 91,4 \% ; 87,7 \% ; 87,7 \%$; 81\%. Nghiên cứu của Lê Thị Sương (2017) trên 32 bệnh nhân UTV điều trị bổ trợ phác đồ 4AC$4 \mathrm{D}$ cho kết quả sống thêm không bệnh sau 1 năm, 2 năm, 3 năm lần lượt là $100 \% ; 91,4 \%$; 86,9\% [8]. Nghiên cứu của Hoàng Thu Hằng điều trị bố trợ phác đồ 4 chu kỳ TC trên 84 bệnh nhân UTV cho tỷ lệ sống thêm không bệnh 1 năm, 2 năm, 3 năm, 4 năm, 4,5 năm lần lượt là 98,8\%; 97,6\%; 96,4\%; 92,9\%; 90,5\%. Nghiên cứu của Stephen E.J và cs (2006) so sánh hiêu quả điều trị giữa hai nhóm bệnh nhân được điều trị bổ trợ phác đồ 4 chu kỳ TC (506 BN) và phác đồ 4 chu kỳ $A C(510 \mathrm{BN})$. Tại thời điểm 5 năm và 7 năm theo dõi, tỷ lệ sống thêm không bênh cao hơn ở nhóm điêu trị phác đồ TC so với phác đồ $\mathrm{AC}(86 \%$ so với $80 \% ; 81 \%$ so với $75 \%, p=$ 0,033). Khi phân tích trên nhóm bệnh nhân trên 65 tuổi, kết quả cũng cho thấy phác đồ TC hiệu quả hơn phác đồ $A C$ về sống thêm không bệnh tại thời điểm 5 năm, 7 năm [9]. Ngoài ra, chúng tổi phân tích thấy bệnh lý mạn tính hay bệnh tim mạch không ảnh hưởng tối kết quả điêu trị của phác đồ TC trên bệnh nhân UTV cao tuổi $(p>0,05)$. Tuy nhiên, DFS có sự khác biệt có ý nghĩa thống kê theo giai đoạn bệnh, giai đoạn I, IIA cho kết quả tốt hơn nhóm giai đoạn IIB, IIIA. Nghiên cứu của Trần Văn Thuấn cho tỷ lệ sống thêm không bệnh 4 năm của bệnh nhân UTV bổ trợ phác đồ $A C$ kết hợp nội tiết là $91,5 \%$ với giai đoạn IIA và giảm xuống còn $63,4 \%$ ở giai đoạn IIIA. Phân nhóm sinh học phân tử không chỉ có có ý nghĩa quan trong trong chỉ định điều trị mà còn giúp tiên lượng UTV, kể cả cho nhóm BN ung thư vú cao tuổi. Nghiên cứu của chúng tôi cũng cho thấy tỷ lệ tái phát di căn của nhóm Her2/neu dương tính và basal-like là $21,8 \%$ và $25 \%$ cao hơn so với nhóm Luminal $A$ và Luminal $B$ là $6,7 \%$ và $4,3 \%$. Trong nghiên cứu này, chúng tôi chỉ lựa chọn các bệnh nhân có Her2/neu dương tính điều trị hóa trị bổ trợ TC mà không có trastuzumab.

\section{KẾT LUÂN}

Phác đồ hóa trị bổ trợ DocetaxelCyclophosphamid cho tỷ lệ sống thêm không bệnh (DFS) cao, tương tự các nghiên cứu trong nước và quốc tế. Do vậy phác đồ có thể được sử dụng phổ biến, rộng răi hơn, không chỉ tại Bệnh viện $\mathrm{K}$ mà có thể ở các cơ sở điều trị ung thư khác cho nhóm BN UTV cao tuổi. Các yếu tố liên quan đến DFS bao gồm giai đoạn bệnh và phân nhóm sinh học phân tử.

\section{TÀI LIÊU THAM KHẢO}

1. Trân Văn Thuấn (2011), Điều trị nội khoa bệnh ung thư vú, Nhà xuất bản Y học, Hà Nội., .

2. Bùi Diệu (2011), Một số bệnh ung thư ở phụ nữ, Nhà xuất bản $Y$ học, Hà Nội., .

3. DeSantis C.E., Fedewa S.A., Sauer A.G., et al. (2016). Breast cancer statistics, 2015: Convergence of incidence rates between black and white women. CA: A Cancer Journal for Clinicians, 66(1), 31-42.

4. Hoi L.V., Chuc N.T., and Lindholm L. (2010). Health-related quality of life, and its determinants, among older people in rural Vietnam. BMC Public Health, 10, 549.

5. Smith L.A., Cornelius V.R., Plummer C.J., et al. (2010). Cardiotoxicity of anthracycline agents for the treatment of cancer: Systematic review and meta-analysis of randomised controlled trials. BMC Cancer, 10(1), 337.

6. Muss H.B., Polley M.-Y.C., Berry D.A., et al. (2019). Randomized Trial of Standard Adjuvant Chemotherapy Regimens Versus Capecitabine in Older Women With Early Breast Cancer: 10-Year Update of the CALGB 49907 Trial. J Clin Oncol 37(26), 2338-2348.

7. Mwangi J., Kulane A., and Van Hoi L. (2015). Chronic diseases among the elderly in a rural Vietnam: prevalence, associated sociodemographic factors and healthcare expenditures. Int J Equity Health, 14

8. Lê Thị Sương (2014). Đánh giá kết quả điều trì bổ trợ ung thư vú giai đoạn II-IIIA bằng phác đồ 4AC- 4D.Trường Đai học Y Hà Nội.

9. Jones S., Holmes F.A., O'Shaughnessy J., et al. (2009). Docetaxel With Cyclophosphamide Is Associated With an Overall Survival Benefit Compared With Doxorubicin and Cyclophosphamide: 7-Year Follow-Up of US Oncology Research Trial 9735. JCO, 27(8), 1177-1183. 